\title{
Phenolic profiling of Veronica spp. grown in mountain, urban and sand soil
}

environments

João C.M. Barreira ${ }^{\mathrm{a}, \mathrm{b}, \mathrm{c}}$, Maria Inês Dias ${ }^{\mathrm{a}, \mathrm{c}}$, Jelena Živkovićd ${ }^{\mathrm{d}}$, Dejan Stojkoviće ${ }^{\mathrm{e}}$, Marina Sokoviće Celestino Santos-Buelga ${ }^{\mathrm{b}, *}$, Isabel C.F.R. Ferreira ${ }^{\mathrm{a}, *}$

${ }^{a}$ CIMO/Escola Superior Agrária, Instituto Politécnico de Bragança, Apartado 1172, 5301-855 Bragança, Portugal.

${ }^{\mathrm{b}}$ GIP-USAL, Facultad de Farmacia, Universidad de Salamanca, Campus Miguel de Unamuno, 37007 Salamanca, Spain.

${ }^{\mathrm{c} R E Q U I M T E / D e p a r t a m e n t o ~ d e ~ C i e ̂ n c i a s ~ Q u i m i c a s, ~ F a c u l d a d e ~ d e ~ F a r m a ́ c i a, ~ U n i v e r s i d a d e ~ d o ~}$ Porto, Rua Jorge Viterbo Ferreira, $n^{\circ} 228$, 4050-313 Porto, Portugal.

${ }^{\mathrm{d} I n s t i t u t e ~ f o r ~ M e d i c i n a l ~ P l a n t ~ R e s e a r c h ~ " D r . ~ J o s i f ~ P a n c ̌ i c ́ ”, ~ T a d e u s ̌ a ~ K o s ̌ c ́ u s ̌ k a ~ 1, ~} 11000$ Belgrade, Serbia.

${ }^{\mathrm{e} D e p a r t m e n t}$ of Plant Physiology, Institute for Biological Research "Siniša Stanković", University of Belgrade, Bulevar Despota Stefana 142, 11000 Belgrade, Serbia.

* Authors to whom correspondence should be addressed (Isabel C.F.R. Ferreira; e-mail: iferreira@ipb.pt, telephone +351273303219, fax +351273325405; e-mail: Celestino SantosBuelga: csb@usal.es; telephone +34923294537; fax +34923294515). 


\begin{abstract}
Veronica (Plantaginaceae) genus is widely distributed in different habitats. Phytochemistry studies are increasing because most metabolites with pharmacological interest are obtained from plants. The phenolic compounds of $V$. montana, $V$. polita and $V$. spuria were tentatively identified by HPLC-DAD-ESI/MS. The phenolic profiles showed that flavones were the major compounds ( $V$. montana: 7 phenolic acids, 5 flavones, 4 phenylethanoids and 1 isoflavone; $V$. polita: 10 flavones, 5 phenolic acids, 2 phenylethanoids, 1 flavonol and 1 isoflavone; $V$. spuria: 10 phenolic acids, 5 flavones, 2 flavonols, 2 phenylethanoids and 1 isoflavone), despite the overall predominance of flavones. $V$. spuria presented the highest contents in all groups of phenolic compounds, except flavones, which did not show differences among the assayed species. The detected differences proved to be significant, as confirmed by objects distribution obtained in PCA. Overall, these species might be considered good sources of phenolic compounds for industrial or pharmacological applications.
\end{abstract}

Keywords: Veronica; Phenolic profiles; HPLC-DAD-ESI/MS, principal component analysis. 


\section{Introduction}

Veronica is a genus of the Plantaginaceae (formerly Scrophulariaceae), which contains nearly 500 species. It is distributed through the Northern Hemisphere and in many parts of the Southern Hemisphere. It is ecologically diverse, ranging from aquatic to dry steppe habitats and from sea level to high alpine regions (Albach, Jensen, Özgökce, \& Grayer, 2005a). The phytochemistry of the genus was previously studied in some species surveyed for their iridoid (Jensen, Albach, Ohno, \& Grayer, 2005; Harput, Genc, Khan, \& Saracoglu, 2011) and phenylethanoid (Taskova, Gotfredsen \& Jensen, 2006; Harput et al., 2011) derivatives and flavonoid glycosides (Taskova, Kokubin, Ryan, Gamock-Jones, \& Jensen, 2010; Saracoglu, Varel, Harput \& Nagatsu, 2004a; Albach, Grayer, Kite, Jensen, 2005b; Taskova, Kokubun, Grayer, Ryan, \& Garnock-Jones, 2008; Taskova et al., 2010; Harput et al., 2011). Iridoid derivatives were mainly found as glucosides, such as aucubin, catalpol (esterified with benzoic and cinnamic acid), mussaenoside and mussaenosidic acid esters (Saracoglu et al., 2004a).

Previously, flavone aglycones such as luteolin, apigenin, chrysoeriol, scutellarein and isoscutellarein were reported in Veronica species. Veronica thymoides subsp. pseudocinerea for instance, was reported as having several flavone and phenol gycosides, a lignin glucoside, iridoid glucosides and steroidal saponins. Glycosilation of these aglycones was usually observed at $5^{\text {th }}$ or $7^{\text {th }}$ position and the acylation of the sugars was another characteristic feature of some glycosides. Actually, the acylated flavone glycosides were reported as chemosystematic markers in the genus Veronica (Saracoglu et al., 2004a).

Veronica species have become prominent due to their traditional uses and biological activities. Previously reports indicated Veronica as being antimicrobial (Stojković et al., 2013), diuretic, wound healing, analgesic, expectorant and antiscorbutic, presenting also acknowledged properties that might be helpful to treat cancer, influenza, hemoptysis, laryngopharyngitis, 
hernia, cough and respiratory diseases (Saracoglu et al., 2004a; Küpeli, Harput, Varel, Yesilada, \& Saracoglu, 2005; Harput et al., 2011).

Herein, we report the identity of phenolic compounds in the aerial parts of relevant Veronica species (Veronica montana, $V$. polita and $V$. spuria) grown in different habitats. The phenolic profile was obtained by high performance liquid chromatography and mass spectrometry and the acquired results were evaluated by principal component analysis in order to conclude if the detected differences were enough to separate each species and also to find the phenolic compounds that most contribute to that clusterization.

\section{Materials and methods}

\subsection{Plant samples}

The aerial flowering parts of $V$. montana, $V$. polita and $V$. spuria were collected from Mountain Goč (central Serbia) in June 2008, Pančevo (south Banat, Vojvodina) in June 2010 and Deliblatska peščara - sand soil (south Banat, Vojvodina) in June 2011, respectively. Plant material was taxonomically determined and deposited in the Herbarium collection of the Institute for Medicinal Plant Research "Dr. Josif Pančić”, Belgrade (voucher specimen numbers were VmZ08-01, VpZ10 and VsZ10 for $V$. montana, V. polita and $V$. spuria, respectively). Plants were harvested during the flowering season. Sample contained material from 25 plants to ensure representative material for analytical testing. Plants were air dried plant and reduced to a fine powder before extraction procedure.

\subsection{Standards and reagents}

HPLC-grade acetonitrile was obtained from Merck KgaA (Darmstadt, Germany). Formic acid was purchased from Prolabo (VWR International, France). The phenolic compound standards 
(caffeic acid, protocatechuic acid, $p$-hydroxybenzoic acid, quercetin-3-O-glucoside, kaempferol3-O-glucoside, luteolin-7- $O$-glucoside, apigenin-7- $O$-glucoside and apigenin-6- $O$-glucoside) were from Extrasynthese (Genay, France). Water was treated in a Milli-Q water purification system (TGI Pure Water Systems, USA).

\subsection{Characterization of phenolic compounds}

The powdered plant samples $(\sim 1 \mathrm{~g})$ were extracted by stirring with $30 \mathrm{~mL}$ of methanol:water 80:20 $(v / v)$, at room temperature, $150 \mathrm{rpm}$, for $1 \mathrm{~h}$. The extract was filtered through Whatman No. 4 paper. The residue was then re-extracted twice with additional portions $(30 \mathrm{~mL})$ of methanol:water 80:20 (v/v). The combined extracts were evaporated at $35{ }^{\circ} \mathrm{C}$ (rotary evaporator Büchi R-210, Flawil, Switzerland) to remove methanol. The aqueous phase was lyophilized and re-dissolved in $20 \%$ aqueous methanol to obtain a final concentration of $5 \mathrm{mg} / \mathrm{mL}$ and filtered through a $0.22-\mu \mathrm{m}$ disposable LC filter disk for high performance liquid chromatography (HPLC-DAD-MS) analysis. The extracts were analysed using a Hewlett-Packard 1100 chromatograph (Agilent Technologies) with a quaternary pump and a diode array detector (DAD) coupled to an HP Chem Station (rev. A.05.04) data-processing station. A Waters Spherisorb S3 ODS-2 $\mathrm{C}_{18}, 3 \mu \mathrm{m}(4.6 \mathrm{~mm} \times 150 \mathrm{~mm})$ column thermostatted at $35{ }^{\circ} \mathrm{C}$ was used. The solvents used were: (A) $0.1 \%$ formic acid in water, (B) acetonitrile. The elution gradient established was isocratic $15 \%$ B for $5 \mathrm{~min}, 15$ to $20 \%$ B over $5 \mathrm{~min}, 20-25 \%$ B over $10 \mathrm{~min}, 25$ $35 \% \mathrm{~B}$ over $10 \mathrm{~min}, 35-50 \%$ for $10 \mathrm{~min}$, and re-equilibration of the column, using a flow rate of $0.5 \mathrm{~mL} / \mathrm{min}$. An injection volume of $100 \mu \mathrm{L}$ was used. Double online detection was carried out in the DAD using $280 \mathrm{~nm}$ and $370 \mathrm{~nm}$ as preferred wavelengths and in a mass spectrometer (MS) connected to HPLC system via the DAD cell outlet.

MS detection was performed in an API 3200 Qtrap (Applied Biosystems, Darmstadt, Germany) equipped with an ESI source and a triple quadrupole-ion trap mass analyzer that was controlled 
by the Analyst 5.1 software. Zero grade air served as the nebulizer gas (30 psi) and turbo gas for solvent drying $\left(400^{\circ} \mathrm{C}, 40 \mathrm{psi}\right)$. Nitrogen served as the curtain $(20 \mathrm{psi})$ and collision gas (medium). The quadrupols were set at unit resolution. The ion spray voltage was set at $-4500 \mathrm{~V}$ in the negative mode. The MS detector was programmed to perform a series of two consecutive modes: enhanced MS (EMS) and enhanced product ion (EPI) analysis. EMS was employed to record full scan spectra to obtain an overview of all of the ions in sample. Settings used were: declustering potential (DP) $-450 \mathrm{~V}$, entrance potential (EP) $-6 \mathrm{~V}$, collision energy (CE) $-10 \mathrm{~V}$. Spectra were recorded in negative ion mode between $\mathrm{m} / \mathrm{z} 100$ and 1000. Analysis in EPI mode was further performed in order to obtain the fragmentation pattern of the parent ion(s) detected in the previous experiment using the following parameters: DP $-50 \mathrm{~V}, \mathrm{EP}-6 \mathrm{~V}, \mathrm{CE}-25 \mathrm{~V}$, and collision energy spread (CES) $0 \mathrm{~V}$.

The phenolic compounds present in the samples were characterized according to their UV and mass spectra and retention times compared with commercial standards when available. For the quantitative analysis of phenolic compounds, a calibration curve was obtained by injection of known concentrations $(1-100 \mu \mathrm{g} / \mathrm{mL})$, further used as " $\mathrm{x}$ " values, of different standards compounds: (I) caffeic acid $\left(\mathrm{y}=611.9 x-4.5733 ; R^{2}=0.999\right)$ (II) protocatechuic acid $(\mathrm{y}=$ $\left.291.10 x-6.4558 ; R^{2}=0.999\right)$; (III) $p$-hydroxybenzoic acid $\left(\mathrm{y}=265.74 x+87.777 ; R^{2}=0.999\right)$; (IV) 5-O-caffeoylquinic acid acid (y = 313.03x-58.2; $\left.R^{2}=0.999\right)$; (V) quercetin-3-O-glucoside $\left(\mathrm{y}=253.52 x-11.615 ; R^{2}=0.999\right) ;(\mathrm{VI})$ kaempferol-3-O-glucoside $\left(\mathrm{y}=288.55 x-4.0503 ; R^{2}=\right.$ 0.999); (VII) luteolin-7-O-glucoside (y = 80.829x - 21.291; $\left.R^{2}=0.999\right)$; (VIII) apigenin-7-Oglucoside $\left(\mathrm{y}=159.62 x+7.5025 ; R^{2}=0.999\right) ;(I X)$ chrysoeriol $\left(\mathrm{y}=307.76 x-1048.2 ; R^{2}=\right.$ 0.999). For compounds I-IV, "y" represents the absorbance at $280 \mathrm{~nm}$; for compounds V-IX, “y” represents the absorbance at $370 \mathrm{~nm}$. Quantification was performed based on DAD results, using $280 \mathrm{~nm}$ for phenolic acids and $370 \mathrm{~nm}$ for flavonoid related compounds. The reference standards used for the quantification of each compound are indicated in table 1. 


\subsection{Statistical analysis}

For each species, three independent samples were used. The purified extracts of each of these samples was injected in duplicate. The results were expressed in mg per g of extract (dw), as mean values \pm standard deviation (SD). All statistical tests were performed at a $5 \%$ significance level using the SPSS software, version 20.0 (IBM Inc).

The fulfillment of the one-way ANOVA requirements, specifically the normal distribution of the residuals and the homogeneity of variance, was tested by means of the Shapiro-Wilk's, and the Levene's tests, respectively. For each parameter, significant differences among mean values were checked by Welch's statistics $(p<0.05$ means that the mean value of a determined phenolic compound had significant differences among the assayed Veronica species). In the cases where statistical significance differences were identified, the dependent variables were compared using Tukey's honestly significant difference (HSD) or Tamhane's T2 multiple comparison tests, when homoscedasticity was verified or not, respectively. For all phenolic compounds present in only 2 species, means were classified using a simple $t$-test, since there were fewer than three groups.

Principal components analysis (PCA) was applied to verify which variables correlate better with each Veronica species. PCA transforms the original, measured variables into new uncorrelated variables called principal components. The first principal component covers as much of the variation in the data as possible. The second principal component is orthogonal to the first and covers as much of the remaining variation as possible, and so on. The number of dimensions to keep for data analysis was evaluated by the respective eigenvalues (which should be greater than one), by the Cronbach's alpha parameter (that must be positive) and also by the total percentage of variance (that should be as higher as possible) explained by the number of components selected. The number of dimensions considered for PCA was chosen in order to allow meaningful interpretations. 


\section{Results and discussion}

The characterization of the phenolic compounds was performed by HPLC-DAD/ESI-MS analysis, and data of the retention time, $\lambda_{\max }$, deprotonated molecule, main fragment ions in $\mathrm{MS}^{2}$, tentative identification and concentration of phenolic acid derivatives and flavonoids are presented in Table 1. Results were expressed in $\mathrm{mg} / \mathrm{g}$ of dried plant considering the different extraction yields for each species $(V$. montana: $\eta=17.77 \% ; V$ polita: $\eta=21.88 \% ;$ V. spuria $: \eta$ $=29.00 \%$, in average). The HPLC phenolic profiles recorded at $280 \mathrm{~nm}$ of $V$. montana (A), $V$. polita (B) and $V$. spuria (C) are given in Figure 1.

UV and mass spectra obtained by HPLC-DAD-ESI/MS analysis showed that these Plantaginaceae species were characterized by the presence of phenolic acids ( $p$-hydroxybenzoyl and hydroxycinnamoyl derivatives), flavonoids and secoiridoids. The analysis of the $\mathrm{MS}^{2}$ fragments revealed $O$ - and $C$-glycosides of flavonoids, specifically derived from flavones (luteolin, apigenin, isoscutellarein, chrysoeriol and acacetin), an isoflavone (genistein) and a flavonol (quercetin). Glycosides substituents consisted of glucuronides, hexosides and pentosides, as deduced from the losses of $176 \mathrm{Da}, 162 \mathrm{Da}$ and $132 \mathrm{Da}$, respectively.

\subsection{Hydroxycinnamoyl derivatives}

Various hydroxycinnamoyl derivatives were observed, especially caffeic acid derivatives, that were tentatively identified according to their characteristic UV spectra, showing maximum wavelength around $324-330 \mathrm{~nm}$, and to the ion at $\mathrm{m} / \mathrm{z} 179$ ([caffeic acid-H]') observed in their $\mathrm{MS}^{2}$ spectra. Compound 1 ( V. montana: $0.111 \mathrm{mg} / \mathrm{g}$ ) was identified as 3-O-caffeoylquinic acid based on its mass spectral data, according to the hierarchical keys described by Clifford et al. (2003). Similarly, compound 5 (V. montana: $0.30 \mathrm{mg} / \mathrm{g} ; \quad$. polita: $0.054 \mathrm{mg} / \mathrm{g}$ ) was identified as 5-O-caffeoylquinic acid by comparison with a standard, and according to its $\mathrm{MS}^{2}$ fragmentation 
pattern as reported by Clifford, Johnston, Knight \& Kuhnert (2003) and Clifford, Knight \& Kuhnert (2005). Compound 9 (V. montana: $0.28 \mathrm{mg} / \mathrm{g} ; V$. spuria: $0.15 \mathrm{mg} / \mathrm{g}$ ) was positively identified as caffeic acid by comparison with a commercial standard. The same criteria were taken into account to identify compound 31 (V. montana: $0.20 \mathrm{mg} / \mathrm{g}),[\mathrm{M}-\mathrm{H}]^{-}$at $\mathrm{m} / \mathrm{z} 515$, as 3,5O-dicaffeoylquinic acid. Compound 3 (V. polita: $0.058 \mathrm{mg} / \mathrm{g}$; V. spuria: $0.32 \mathrm{mg} / \mathrm{g}$ ) presented a deprotonated molecule $[\mathrm{M}-\mathrm{H}]^{-}$at $m / z 341$ and similar fragmentation pattern, with the loss of 162 $\mathrm{u}$ (hexosyl moiety), yielding a peak at $m / z 179 \mathrm{u}$ ([caffeic acid-H] $\left.]^{-}\right)$and other two fragments at $m / z 161$ ([caffeic acid-H-H $\mathrm{H}_{2} \mathrm{O}^{-}$) and 135 ([caffeic acid- $\left.\left.\mathrm{H}-\mathrm{CO}_{2}\right]^{-}\right)$, being assigned as hexosylcaffeic acid. Compound 18 (V. spuria: $0.25 \mathrm{mg} / \mathrm{g}$ ) gave a deprotonated molecule [M-H] ${ }^{-}$at $\mathrm{m} / \mathrm{z}$ 503 yielding $\mathrm{MS}^{2}$ fragments at $\mathrm{m} / \mathrm{z} 341$ and 179 from the successive loss of two $162 \mathrm{u}$, which could correspond either to hexosyl or to caffeoyl moieties, as well as at $m / z 161$ and 135 , characteristic of caffeic acid. Since the presence of two hexosyl residues in the compound can be discarded, as much earlier elution would be expected (i.e., before compound 3), the compound might be interpreted as a dicaffeoyl-hexose (also supported by the absence $\mathrm{CO}_{2}$ loss).

The characteristic fragments at $m / z 179,161$ and 135 were also observed in compound 7 ( $V$. polita: $0.048 \mathrm{mg} / \mathrm{g} ;$ V. spuria: $0.19 \mathrm{mg} / \mathrm{g}$ ), with a deprotonated molecule $[\mathrm{M}-\mathrm{H}]^{-}$at $\mathrm{m} / \mathrm{z} 383$, and compound 8 (V. spuria: $0.42 \mathrm{mg} / \mathrm{g}$ ), with a deprotonated molecule $[\mathrm{M}-\mathrm{H}]^{-}$at $\mathrm{m} / \mathrm{z} 399$, indicating that these also correspond to caffeic acid derivatives; compound 7 was tentatively identified as acetyl-hexosyl-caffeic acid, but the structure of compound 8 could not be determined.

Compound 21 (V. montana: $0.067 \mathrm{mg} / \mathrm{g} ;$ V. polita: $0.30 \mathrm{mg} / \mathrm{g} ;$ V. spuria: $0.48 \mathrm{mg} / \mathrm{g}),[\mathrm{M}-\mathrm{H}]^{-}$at $m / z 623$, was tentatively identified as acteoside (also known as verbascoside) based on the UV spectrum and $\mathrm{MS}^{2}$ fragmentation pattern as reported by Li et al. (2005) and Qi et al. (2013). Thus, the $\mathrm{MS}^{2}$ fragment ion at $m / z 461$ would result from the loss of a caffeoyl moiety ([M-H$162]^{-}$); the weak ion at $m / z 315$ was consistent with the further loss of a rhamnose unit, and ions at $m / z 161$ and 135 are coherent with the presence of caffeic acid. Similar characteristics were 
observed for compound 23 ( $V$. montana: $0.11 \mathrm{mg} / \mathrm{g}$ ) which was tentatively identified as isoacteoside according to its elution order compared to acteoside (Li et al., 2005). This type of phenylethanoid glycosides has been previously reported in Veronica species (Jensen et al., 2005; Johansen, Larsen, Mattebjerg, Gotfredsen, \& Jensen 2007).

\subsection{Flavonoids}

Early studies by Grayer-Barkmeijer (1978) and Tomás-Barberán, Grayer-Barkmeijer, Gil \& Harborne (1988) have indicated that the flavonoid composition in Veronica genus is characterised by the flavones luteolin, chrysoeriol and apigenin, specifically 7-glycosides (i.e., glucosides and glucuronides) and 6- and 8-hydroxyflavones, such as 6-hydroxyluteolin, scutellarein (6-hydroxyapigenin) and isoscutellarein (8-hydroxyapigenin) (Saracoglu, Harput, \& Ogihara, 2004b). The presence of luteolin-7-O-glucoside, corresponding to compound 27 ( $V$. montana: $2.5 \mathrm{mg} / \mathrm{g} ;$ V. polita: $0.58 \mathrm{mg} / \mathrm{g} ;$ V. spuria: $2.9 \mathrm{mg} / \mathrm{g}$ ) and apigenin-7-O-glucoside (compound 32, V. polita: $0.42 \mathrm{mg} / \mathrm{g} ; V$. spuria: $1.0 \mathrm{mg} / \mathrm{g}$ ) was confirmed by their UV and mass spectra characteristics and comparison with commercial standards. Compound 28 (V.polita: 0.51 $\mathrm{mg} / \mathrm{g}$ ) could also correspond to an isoscutellarein-hexoside (based on its deprotonated molecule and fragmentation pattern, but especially UV maxima), but sugar type and location could not be identified. Compounds 33 (V. montana: $0.19 \mathrm{mg} / \mathrm{g}$ ) and 34 (V. spuria: $1.5 \mathrm{mg} / \mathrm{g}$ ) were identified as glucuronides of apigenin $\left([\mathrm{M}-\mathrm{H}]^{-}\right.$at $\left.\mathrm{m} / \mathrm{z} 445\right)$ and luteolin $\left([\mathrm{M}-\mathrm{H}]^{-}\right.$at $\left.\mathrm{m} / \mathrm{z} 461\right)$, respectively. In both cases the presence of the glucuronyl moiety was inferred by the loss of a fragment of $176 \mathrm{u}$ leading to the corresponding aglycone. Those compounds were tentatively identified as the respective 7-O-glucuronides based on the previous observations of Grayer-Barkmeijer (1978) and Tomás-Barberán et al. (1988) about the usual presence of such derivatives in Veronica species. Compounds 35 (V. montana: $0.86 \mathrm{mg} / \mathrm{g})$ and $36(V$. montana: $3.0 \mathrm{mg} / \mathrm{g})$ presented the same deprotonated molecule $[\mathrm{M}-\mathrm{H}]^{-}$at $m / z 475$ releasing $\mathrm{MS}^{2}$ fragments at $m / z 299$ ([M-176] $\left.]^{-}\right)$ 
and 284 ([M-176-15]'), attributed to the successive loss of a glucuronyl moiety and a methyl group. These features and their characteristic UV spectra with $\lambda_{\max }$ at $346-348 \mathrm{~nm}$ (Beninger \& Hall, 2005) allowed identifying them as chrysoeriol glucuronides. According to the prevalence of each isomer in Scrophulariaceae family, they were tentatively identified as chrysoeriol-5-Oglucuronide and chrysoeriol-7-O-glucuronide (Tomás-Barberán et al., 1988). Compound 39 ( $V$. montana: $0.33 \mathrm{mg} / \mathrm{g}$ ) presented a deprotonated molecule [M-H] ${ }^{-}$at $m / z 459$, releasing two $\mathrm{MS}^{2}$ fragment ions at $m / z 283\left([\mathrm{M}-176-\mathrm{H}]^{-}\right.$, loss of a glucuronyl moiety) and 268 ([M-176-15-H]', further loss of a methyl group), suggesting that it could correspond to a methylapigenin- $O$ glucuronide. Although the position of the glucuronyl and methyl substituents cannot be deduced from the available data, the common presence of acacetin (i.e., 4'-methylapigenin) has also been described in Scrophulariaceae (Tomás-Barberán et al., 1988) including Veronica species (Grayer-Barkmeijer, 1978), leading to the tentative identification as acacetin-7-O-glucuronide.

Compound 37 (V. polita: $3.2 \mathrm{mg} / \mathrm{g}$ ) showed a deprotonated molecule $[\mathrm{M}-\mathrm{H}]^{-}$at $\mathrm{m} / \mathrm{z} 651$, releasing $\mathrm{MS}^{2}$ fragments at $\mathrm{m} / \mathrm{z} 609$ (allowing its identification as an acetyl derivative), $\mathrm{m} / \mathrm{z} 447$ ([M-H-42-162]', loss of a hexosyl moiety) and at $m / z 285$ ([M-H-42-162-162]', loss of a second hexosyl moiety). This fragmentation pattern indicates the existence of an $O$-acetylglycosyl residue (Petreska et al., 2011) with the detection of the intermediate ion [M-H-42-180] at $\mathrm{m} / \mathrm{z}$ 429 pointing to the presence of the acetyl group on the external sugar (Karioti, Bolognesi, Vincieri, \& Bilia, 2010). The ion at $\mathrm{m} / \mathrm{z} 285$ corresponding to the aglycone might be interpreted as either luteolin or hydroxyapigenin. Nevertheless, the characteristic UV spectrum with maxima at 276, 306 and $326 \mathrm{~nm}$ was in agreement with those described for isoscutellarein glycosides in Veronica species (Saracoglu et al., 2004b). Furthermore, the identification of isoscutellarein derivatives in Veronica species by RMN techniques (Albach et al., 2005b), and the fragmentation profile of the compound that coincided with that reported by Pereira, Domingues, Silva \& Cardoso (2012) allowed the tentative identification of compound 37 as isoscutellarein 7- 
$O$ - $\left(6^{\prime \prime}-O\right.$-acetyl $)-\beta$-allosyl- $\left(1^{\prime \prime} \rightarrow 2^{\prime \prime}\right)-\beta$-glucoside, the most abundant compound in $V$. polita. Similar UV and mass spectra characteristics were found for compound 29 (V. polita: $0.44 \mathrm{mg} / \mathrm{g}$ ), although the lack of the acetyl group, which was thus tentatively identified as isoscutellarein-7$O$-allosyl-glucoside. Compounds 20 (V. polita: $0.282 \mathrm{mg} / \mathrm{g}),[\mathrm{M}-\mathrm{H}]^{-}$at $\mathrm{m} / z$ 609, and $30(V$. polita: $0.92 \mathrm{mg} / \mathrm{g}),[\mathrm{M}-\mathrm{H}]^{-}$at $\mathrm{m} / \mathrm{z} 651$ showed the same deprotonated molecule and similar $\mathrm{MS}^{2}$ fragments as compounds 29 and 37, respectively, so that it could be speculated that compounds 20 and 30 are isomers of compounds 29 and 37, but glycosylated on different positions of the aglycone. On the other hand, the UV spectra of compounds 20 and 30 did not show the additional maximum/shoulder around $300 \mathrm{~nm}$ derived of the effect of the 8-hydroxylation (Campos and Markham, 2007). Nevertheless, since that effect could be abolished by substitution of the 8-hydroxyl group (Campos \& Markham, 2007), compounds 20 and 30 might be speculated as isoscutellarein derivatives glycosylated on position 8 , although there are not further elements to support that supposition. Compound 38 (V. spuria: $0.17 \mathrm{mg} / \mathrm{g}$ ) showed the same deprotonated molecule $\left([\mathrm{M}-\mathrm{H}]^{-}\right.$at $m / z$ 609) and fragmentation pattern and similar UV spectrum as compound 20 (despite some changes due to the overlapping spectra of caffeic acid and isoscutellarein), but eluting at a longer retention time, which might indicate that one of the losses of $162 \mathrm{u}$ observed in its $\mathrm{MS}^{2}$ fragmentation is due to a caffeoyl residue instead of an hexosyl one. The $\lambda_{\max }$ at $334 \mathrm{~nm}$ in its UV spectrum would support that the compound derives from isoscutellarein (i.e., 6- or 8-hidroxyapigenin) rather than from luteolin ( $\lambda_{\max }$ around $350 \mathrm{~nm}$ ). Thus, it was tentatively identified as isoscutellarein- $O$-caffeoylglucoside. Compound 26 ( $V$. spuria: $1.2 \mathrm{mg} / \mathrm{g}),[\mathrm{M}-\mathrm{H}]^{-}$at $\mathrm{m} / z$ 593, showed the same $\mathrm{MS}^{2}$ fragments at $\mathrm{m} / z$ at 447 and 285 as compound 38, from the successive loss of $146 \mathrm{u}$ and $162 \mathrm{u}$ (attributed to rhamnosyl and hexosyl moieties, respectively). Nevertheless, the UV spectrum with $\lambda_{\max }$ at $350 \mathrm{~nm}$ seems to support the presence of luteolin rather than isoscutellarein as aglycone, so that the compound was tentatively identified as luteolin-O-rhamosyl-hexoside. 
Quercetin derivatives were also detected in $V$. polita and $V$. spuria samples. Compound 24 ( $V$. polita: $0.26 \mathrm{mg} / \mathrm{g}$ ) was positively identified as quercetin $3-O$-glucoside according to its retention time, mass and UV-vis characteristics by comparison with the commercial standard. Compounds 17 and 19 (V. spuria: $0.14 \mathrm{mg} / \mathrm{g}$ and $0.63 \mathrm{mg} / \mathrm{g}$, respectively) also showed absorption and mass spectra coherent with quercetin glycosides. Compound 17 was tentatively identified as a quercetin- $O$-dihexoside and compound 19 as a quercetin- $O$-hexoside, based on their deprotonated molecules; according to the position of band I, it is safe to say that all these compounds are glycosylated in position 3, but the precise identity of the sugar substituents could not be established in any of them.

Compounds 10, 14 and 16 ( $V$. polita: $0.050 \mathrm{mg} / \mathrm{g}, 0.21 \mathrm{mg} / \mathrm{g}$ and $0.11 \mathrm{mg} / \mathrm{g}$, respectively) were identified as $C$-glycosylated derivatives. This type of compounds is characterized by the loss of characteristic fragments from the cleavage of the sugar pyrano ring, namely $-120 \mathrm{u}$ and $-90 \mathrm{u}$ in the case of hexosides (Ferreres, Silva, Andrade, Seabra, \& Ferreira, 2003). Compound 10 presented a deprotonated molecule $[\mathrm{M}-\mathrm{H}]^{-}$at $\mathrm{m} / \mathrm{z}$ 593, showing characteristic fragment ions at $m / z 503(-90 \mathrm{u}), 473(-120 \mathrm{u}), 383(-120-90 \mathrm{u})$ and $353(-120-120 \mathrm{u})$. The ion at $m / z 353$ has been associated to apigenin aglycone bearing some sugar residues $(270+83 \mathrm{u})$ that remained attached to it (Ferreres et al., 2003; Ferreres, Llorach, \& Gil-Izquierdo, 2004). Compounds 14 and 16 presented deprotonated molecules $[\mathrm{M}-\mathrm{H}]^{-}$at $m / z$ 563, also releasing $\mathrm{MS}^{2}$ fragment ions corresponding to loss of 90 and $120 \mathrm{u}(\mathrm{m} / \mathrm{z}$ at 473 and 443), characteristic of $C$-hexosyl flavones, and at $\mathrm{m} / \mathrm{z} 383$ and 353 that might correspond to the apigenin aglycone plus linked sugar residues, respectively (Ferreres et al., 2003). According to these characteristics and the fact that no relevant fragments derived from the loss of complete hexosyl $(-162 \mathrm{u})$ or pentosyl residues ($132 \mathrm{u})$ were detected, suggesting the existence of $O$-liked sugars, the compounds were tentatively identified as apigenin- $C$-hexoside- $C$-hexoside (compound 10) and apigenin- $C$ hexoside- $C$-pentoside (compounds 14 and 16). 
Finally, compound 22 (V. montana: $0.041 \mathrm{mg} / \mathrm{g} ;$ V. polita: $0.28 \mathrm{mg} / \mathrm{g} ;$ V. spuria: $0.40 \mathrm{mg} / \mathrm{g}$ ) was associated to a possible isoflavone derivative based on its characteristic of UV spectrum showing maximum absorption around 260 and $330 \mathrm{~nm}$ (Bórquez, Kennelly, \& Simirgiotis, 2013). This compound presented a deprotonated molecule $[\mathrm{M}-\mathrm{H}]^{-}$at $m / z 449$, releasing an $\mathrm{MS}^{2}$ fragment at $\mathrm{m} / \mathrm{z} 269$ that might correspond to genistein. The identity of the residue(s) attached to aglycone, corresponding to a loss of $-180 \mathrm{u}$, remained unknown.

\section{Other phenolic derivatives}

Compound 4 (V. montana: $1.6 \mathrm{mg} / \mathrm{g}$; V. spuria: $0.26 \mathrm{mg} / \mathrm{g}$ ) was identified as protocatechuic acid by comparing its UV spectrum and retention time with those of a commercial standard. Similarly, compound 6 ( $V$. montana: $0.18 \mathrm{mg} / \mathrm{g} ; V$. polita: $0.076 \mathrm{mg} / \mathrm{g})$ was identified as $p$ hydroxybenzoic acid by comparing its UV spectrum and retention time with a commercial standard.

Compounds 2 (V. spuria: $0.52 \mathrm{mg} / \mathrm{g}), 12$ (V. montana: $1.4 \mathrm{mg} / \mathrm{g}$, V. polita: $0.67 \mathrm{mg} / \mathrm{g}$, V. spuria: $1.6 \mathrm{mg} / \mathrm{g}$ ), 13 and 15 (V. spuria: $0.41 \mathrm{mg} / \mathrm{g}$ and $0.34 \mathrm{mg} / \mathrm{g}$, respectively), were associated to protocatechuic acid derivatives based on their UV spectra similar to this benzoic acid and the characteristic $\mathrm{MS}^{2}$ fragments observed at $m / z 153$ ([protocatechuic acid-H] ) and 109 ([protocatechuic acid-H-CO $]^{-}$). Despite some of the product ions observed in their fragmentations corresponded to common losses such as -162 mu (hexosyl moiety) in compounds 12 and 13 , or $-42 \mathrm{u}\left(\mathrm{C}_{2} \mathrm{H}_{2} \mathrm{O}\right.$ residue $)$ in compound 2, their precise structures could not be concluded and remain to be identified. They were named as protocatechuic acid derivatives I-IV. Compound 25 (V. montana: $0.83 \mathrm{mg} / \mathrm{g}, V$. polita: $0.10 \mathrm{mg} / \mathrm{g}$; $V$. spuria: $1.3 \mathrm{mg} / \mathrm{g}$ ) presented a deprotonated molecule at $\mathrm{m} / \mathrm{z} 523$ and a $\mathrm{MS}^{2}$ fragmentation pattern with three fragments at $\mathrm{m} / \mathrm{z}$ 179, 161 and 135 characteristic of caffeic acid derivatives, together with another product ion at $m / z 361$ (-162 u, possible loss of a hexosyl moiety). These characteristics are coherent with the 
structure of verminoside (Figure 2) consisting of the iridoid catalpol linked to caffeic acid. Actually, iridoids are a type of compounds commonly reported in Veronica species (Harput, Saracoglu, Inoue, \& Ogihara, 2002; Jensen et al., 2005; Saracoglu \& Harput, 2012), and the presence of various catalpol derivatives in Veronica species, including caffeoyl-catalpol, was already reported by Grayer-Barkmeijer (1973).

Compound 11 ( $V$. montana: $0.30 \mathrm{mg} / \mathrm{g}$ ) was also identified as belonging to the class of iridoids. It presented a deprotonated molecule at $m / z$ 685, releasing $\mathrm{MS}^{2}$ fragments at $\mathrm{m} / z 523$ ([M-H162]', loss of a hexosyl moiety), $m / z 361$ ([M-H-162-162]', loss of a second hexosyl moiety), and the characteristic fragments at $m / z 179,161$ and 135 indicating the presence of caffeic acid. The $\mathrm{MS}^{2}$ spectrum of the deprotonated molecule did not produce ions corresponding to the losses of 70,102 or $224 \mathrm{u}$, confirming that the secoiridoid ring is not stabilized by forming acetal. This compound was tentatively identified as $6-O$-[ $\beta$-D-glucopyranosyl-( $1 \rightarrow 4)$-caffeoyl $]$ catalpol, also known as speedoside, that was already detected in Veronica genus (Jensen, Albach, Ohno, \& Grayer, 2005).

In general, the analysed species presented significant differences in their phenolic profiles, either qualitatively as well as quantitatively. $V$. spuria had the highest content in phenolic acids, mainly due to protocatechuic acid II (compound 12). V. montana gave similar phenolic acid amounts, with particular relevance for protocatechuic acid, which was previously reported as the major phenolic acid in this species (Stojković et al., 2013). Flavones were, in fact, the most abundant group of phenolics, presenting approximately the same amount in the three species. The detected amounts were mainly due to chrysoeriol-7-O-glucuronide (compound 36 ) in $V$. montana, isoscutellarein 7-O-(6"-O-acetyl)- $\beta$-allosyl-( $\left(1^{\prime \prime} \rightarrow 2^{\prime \prime}\right)-\beta$-glucoside (compound 37) in $V$. polita and luteolin-7-O-glucoside (compound 27) in $V$. spuria. The mass spectra for the most abundant 
compound in each plant species, 36 in V. montana, 37 in $V$. polita and 27 in $V$. spuria are presented as supplementary material.

These differences in phenolic profiles might be attributed to different environments in which plants were collected and their adaptations to different environmental conditions. Although belonging to the same genus, $V$. montana is typical from mountain area; $V$. polita is commonly found in the urban area of the city of Pančevo and $V$. spuria used in this study was collected from the sandy terrain - Deliblatska peščara. In fact, many factors influence phenolic accumulation in plants, but water availability, as well as application of exogenous growth factors, exposure to various light sources and the presence of fungal or predatory pressures, cause the highest changes in phenolic biosynthesis dynamics (Cohen \& Kennedy, 2010).

To confirm if the profiled differences were enough to distinguish the three Veronica species, finding also the phenolic compounds that most contribute to that separation, a principal components analysis (PCA) was applied. The plot of component loadings (Figure 3) indicates that the first two dimensions (first: Cronbach's $\alpha, 0.972$; eigenvalue, 19.894; second: Cronbach’s $\alpha, 0.959$; eigenvalue, 16.036) account for most of the variance of all quantified variables (45.2\% and $36.4 \%$, respectively). The included variance would ideally be higher, but the inclusion of additional dimensions would not allow a so meaningful interpretation.

Groups corresponding to each species were clearly separated, as it could be expected from Table 1. Group corresponding to $V$. montana is mainly characterized by the high amounts of $3,5-O$ dicaffeoylquinic acid (31), speedoside (11), isoacteoside (23), 5-O-caffeoylquinic acid (5), 3-Ocaffeoylquinic acid (1), protocatechuic acid (4), caffeic acid (9), both chrysoeriol glucuronides (35 and 36), acacetin-7-O-glucuronide (39) and apigenin-7-O-glucuronide (33) and low contents in genistein derivative (22), acteoside (21), apigenin-7-O-glucoside (32) and grouped flavonols. Regarding $V$. polita, the high contents in apigenin- $C$-hexoside- $C$-hexoside (10), apigenin- $C$ hexoside- $C$-pentosides (14 and 16), isoscutellarein- $O$-hexoside-hexoside (20), isoscutellarein- 
hexoside (28) and isoscutellarein- $O$-acetylhexosyl-hexoside (30) and the low contents in verminoside (25), luteolin- $O$-glucuronide (34), protocatechuic acid derivative II (12) and grouped phenolic acids, phenylethanoids and phenolic compounds, were the distinctive features. Finally, V. spuria detached for its high amounts in acetyl-hexosyl-caffeic acid (7), hexosylcaffeic acid (3), protocatechuic acid derivatives I, III and IV (1, 13 and 15), caffeic acid derivative (8), dicaffeoyl-hexose (18), quercetin-hexoside (19), quercetin-O-di-hexoside (17), luteolin- $O$-rhamnosyl-hexoside (26) and isoscutellarein-O-caffeoylglucoside (38) and the low contents in $p$-hydroxybenzoic acid (6), 3,5-O-dicaffeoylquinic acid (31), speedoside (11), isoacteoside (23), 5-O-caffeoylquinic acid (5), 3-O-caffeoylquinic acid (1), both chrysoeriol glucuronides (35 and 36), acacetin-7-O-glucuronide (39) and apigenin-7-O-glucuronide (33).

Either way, considering the acknowledge bioactivity of most of the identified phenolic compounds, these Veronica species might be considered as good starting materials for different industrial or pharmacological applications.

\section{Acknowledgements}

The authors are grateful to Fundação para a Ciência e a Tecnologia (FCT, Portugal) for financial support to CIMO (strategic project PEst-OE/AGR/UI0690/2011). J.C.M. Barreira and M.I. Dias thank FCT, POPH-QREN and FSE for their grants (SFRH/BPD/72802/2010 and SFRH/BD/84485/2012, respectively). The GIP-USAL is financially supported by the Spanish Government through the Consolider-Ingenio 2010 Programme (FUN-C-FOOD, CSD200700063). The authors are also grateful to the Serbian Ministry of Education, Science and Technological Development for financial support (Grant Numbers 173032 and 46013). 


\section{References}

Albach, D.C., Jensen, S.R., Özgökce, F., \& Grayer, R.J. (2005a). Veronica: Chemical characters for the support of phylogenetic relationships based on nuclear ribosomal and plastid DNA sequence data. Biochemical Systematics and Ecology, 33, 1087-1106.

Albach, D.C., Grayer, R.J., Kite, G.C., \& Jensen, S.R. (2005b). Veronica: Acylated flavone glycosides as chemosystematic markers. Biochemical Systematics and Ecology, 33, 11671177.

Beninger, C.W. \& Hall, J.C. (2005). Allelopathic activity of luteolin 7-O- $\beta$-glucuronide isolated from Chrysanthemum morifolium L. Biochemical Systematics and Ecology, 33, 103-111.

Bórquez, J., Kennelly, E.J., \& Simirgiotis, M.J. (2013). Activity guided isolation of isoflavones and hyphenated HPLC-PDA-ESI-ToF-MS metabolome profiling of Azorella madreporica Clos. from northern Chile. Food Research International, 52, 288-297.

Campos, M.G. \& Markham, K.R. (2007). Structure information from HPLC and on-line measured absorption spectra. Flavones, flavonols and phenolic acids. Coimbra University Press, Coimbra, Portugal; 118 pp.

Clifford, M.N., Johnston, K.L., Knight, S., \& Kuhnert, N.A. (2003). A hierarachical scheme for LC-MS $^{\mathrm{n}}$ identification of chlorogenic acids. Journal of Agricultural and Food Chemistry, 51, 2900-2911.

Clifford, M.N., Knight, S., \& Kuhnert, N.A. (2005). Discriminating between the six isomers of dicaffeoylquinic acid by LC-MS ${ }^{\mathrm{n}}$. Journal of Agricultural and Food Chemistry, 53, $3821-3832$.

Cohen, S.D. \& Kennedy, J.A. (2010). Plant metabolism and the environment: implications for managing phenolics. Critical Reviews in Food Science and Nutrition, 50, 620-643. 
Ferreres, F., Llorach, R., \& Gil-Izquierdo, A. (2004). Characterization of the interglycosidic linkage in di-, tri-, tetra- and pentaglycosylated flavonoids and differentiation of positional isomers by liquid chromatography/electrospray ionization tandem mass spectrometry. Journal of Mass Spectrometry, 39, 312-321.

Ferreres, F., Silva, B.M., Andrade, P.B., Seabra, R.M., \& Ferreira, M.A. (2003). Approach to the study of $C$-glycosyl flavones by ion trap HPLC-PAD-ESI/MS/MS: application to seeds of quince (Cydonia oblonga). Phytochemical Analysis, 14, 352-359.

Grayer-Barkmeijer, R.J. (1973). A Chemosystematic Study of Veronica: Iridoid Glucosides. Biochemical Systematics and Ecology, 1, 101-110.

Grayer-Barkmeijer, R.J. (1978). Flavonoids in Parahebe and Veronica: a chemosystematic study. Biochemical Systematics and Ecology, 6, 131-137.

Harput, U.S., Genc, Y., Khan, N., \& Saracoglu, I. (2011). Radical scavenging effects of different Veronica species. Records of Natural Products, 5, 100-107.

Harput, U.S., Saracoglu, I., Inoue, M., \& Ogihara, I. (2002). Phenylethanoid and iridoid glycosides from Veronica persica. Chemical and Pharmaceutical Bulletin, 50, 869-871.

Jensen, S.R., Albach, D.C., Ohno, T., \& Grayer, R.J. (2005). Veronica: Iridoids and cornoside as chemosystematic markers. Biochemical Systematics and Ecology, 33, 1031-1047.

Johansen, M., Larsen, T.S., Mattebjerg, M.A., Gotfredsen, C.H., \& Jensen, S.R. (2007). Chemical markers in Veronica sect. Hebe. Biochemical Systematics and Ecology, 35, 614-620.

Karioti, A., Bolognesi, L., Vincieri, F.F., \& Bilia, A.R. (2010). Analysis of the constituents of aqueous preparations of Stachys recta by HPLC-DAD and HPLC-ESI-MS. Journal of Pharmaceutical and Biomedical Analysis, 53, 15-23. 
Küpeli, E., Harput, U.S., Varel, M., Yesilada, E., \& Saracoglu, I. (2005). Bioassay guided isolation of iridoid glucosides with antionociceptive and anti-inflammatory activities from Veronica anagallisaquatica L. Journal of Ethnopharmacology, 102, 170-176.

Li, L., Tsao, R., Liu, Z., Liu, S., Yang, R., Young, J.C., Zhu, H., Deng, Z., Xie, M., \& Fu, Z. (2005). Isolation and purification of acteoside and isoacteoside from Plantago psyllium L. by high-speed counter-current chromatography. Journal of Chromatography A, 1063, 161-169.

Pereira, O.R., Domingues, M.R.M., Silva, A.M.S., \& Cardoso, S.M. (2012). Phenolic constituents of Lamium album: Focus on isoscutellarein derivatives. Food Research International, 48, 330-335.

Petreska, J., Stefova, M., Ferreres, F., Moreno, D.A., Tomás-Barberán, F.A., Stefkov, G., Kulevanova, S., Gil-Izquierdo, A. (2011). Potential bioactive phenolics of Macedonian Sideritis species used for medicinal "Mountain Tea". Food Chemistry, 125, 13-20.

Qi, M., Xiong, A., Li, P., Yang, Q., Yang, L., Wang, Z. (2013). Identification of acteoside and its major metabolites in rat urine by ultra-performance liquid chromatography combined with electrospray ionization quadrupole time-of-flight tandem mass spectrometry. Journal of Chromatography B, 940, 77-85.

Saracoglu, I. \& Harput, U.S. (2012). In vitro cytotoxic activity and structure activity relationships of iridoid glucosides derived from Veronica species. Phytotherapy Research, 26, 148-152.

Saracoglu, I., Varel, M., Harput, S., \& Nagatsu, A. (2004a). Acylated flavonoids and phenol glycosides from Veronica thymoides subsp. pseudocinera. Phytochemistry, 65, 23792385.

Saracoglu, I., Harput, U.S., \& Ogihara, Y. (2004b). Acylated flavone glycosides from Veronica pectinata var. glandulosa and $V$. persica. Turkish Journal of Chemistry, 28, 751-759. 
Stojković, D.S., Živković, J., Soković, M., Glamočlija, J., Ferreira, I.C.F.R., Janković, T. \& Maksimović, Z. (2013). Antibacterial activity of Veronica montana L. extract and of protocatechuic acid incorporated in a food system. Food and Chemical Toxicology, 55, 209-213.

Taskova, R.M., Gotfredsen, C.H., \& Jensen, S.R. (2006). Chemotaxonomy of Veroniceae and its allies in the Plantaginaceae. Phytochemistry, 67, 286-301.

Taskova, R.M., Kokubun, T., Grayer, R.J., Ryan, K.G., \& Garnock-Jones, P.J. (2008). Flavonoid profiles in the Heliohebe group of New Zealand Veronica (Plantaginaceae). Biochemical Systematics and Ecology, 36, 110-116.

Taskova, R.M., Kokubun, T., Ryan, K.G., Gamock-Jones, P.J., \& Jensen, S.R. (2010). Phenylethanoid and iridoid glycosides in the New Zealand Snow Hebes (Veronica, Plantaginaceae). Chemical \& Pharmaceutical Bulletin, 58, 703-711.

Tomás-Barberán, F.A., Grayer-Barkmeijer, R.J., Gil, M.I., \& Harborne, J.B. (1988). Distribution of 6-hydroxy-, 6-methoxy- and 8-hydroxyflavone glycosides in the Labiatae, the Scrophulariaceae and related families. Phytochemistry, 27, 2631-2645. 
Table 1.Retention time (Rt), wavelengths of maximum absorption $\left(\lambda_{\max }\right)$, mass spectral data, relative abundances of fragment ions, tentative identification and quantification of the phenolic compounds $V$. montana, $V$. polita and $V$. spuria methanolic extracts.

\begin{tabular}{|c|c|c|c|c|c|c|c|c|c|}
\hline \multirow{2}{*}{ Peak } & \multirow{2}{*}{ Rt (min) } & \multirow{2}{*}{$\lambda \max (\mathrm{nm})$} & \multirow{2}{*}[\mathrm{M}-\mathrm{H}]{$^{-}(m / z)$} & \multirow{2}{*}{$\operatorname{MS}^{2}(m / z)$} & \multirow{2}{*}{ Tentative identification } & \multicolumn{3}{|c|}{ Quantification (mg/g of dried plant) } & \multirow{2}{*}{$\begin{array}{l}\text { Standard used } \\
\text { for quantification }\end{array}$} \\
\hline & & & & & & V. montana & V.polita & V. spuria & \\
\hline \multicolumn{10}{|c|}{ Veronica montana } \\
\hline 1 & 5.4 & $\operatorname{sh} 298 / 326$ & 353 & 191(100), 179(67), 173(4), 161(5), 135(45) & 3-O-caffeoylquinic acid & $0.111 \pm 0.003$ & - & - & IV \\
\hline 2 & 5.8 & $224 / 263 / 294$ & 373 & 237(100), 195(7), 153(30), 109(7) & Protocatechuic acid derivative I & - & - & $0.52 \pm 0.01$ & II \\
\hline 3 & 6.0 & $\operatorname{sh} 298 / 328$ & 341 & 179(41), 161(100), 135(17) & Hexosyl-caffeic acid & - & $0.058 \pm 0.005 \mathrm{~b}$ & $0.32 \pm 0.02 \mathrm{a}$ & I \\
\hline 4 & 6.4 & $228 / 260 / 294$ & 153 & $109(100)$ & Protocatechuic acid* & $1.6 \pm 0.1 \mathrm{a}$ & - & $0.26 \pm 0.01 \mathrm{~b}$ & II \\
\hline 5 & 8.5 & $\operatorname{sh} 298 / 326$ & 353 & 191(100), 179(3), 161(3), 135(3) & 5-O-Caffeoylquinic acid* & $0.30 \pm 0.02 \mathrm{a}$ & $0.054 \pm 0.005 \mathrm{~b}$ & - & IV \\
\hline 6 & 9.7 & 256 & 137 & $93(100)$ & $p$-Hydroxybenzoic acid* & $0.18 \pm 0.02 \mathrm{a}$ & $0.076 \pm 0.002 \mathrm{~b}$ & - & III \\
\hline 7 & 10.2 & $296 / 326$ & 383 & 179(5), 161(100), 135(5) & Acetyl-hexosyl-caffeic acid & - & $0.038 \pm 0.004 \mathrm{~b}$ & $0.19 \pm 0.02 \mathrm{a}$ & I \\
\hline 8 & 10.7 & $300 / 326$ & 399 & 237(100), 179(13), 161(92),135(8) & Caffeic acid derivative & - & - & $0.42 \pm 0.03$ & I \\
\hline 9 & 11.9 & $\operatorname{sh} 298 / 324$ & 179 & $135(100)$ & Caffeic acid* & $0.28 \pm 0.02 \mathrm{a}$ & - & $0.15 \pm 0.01 \mathrm{~b}$ & I \\
\hline 10 & 12.6 & $266 / 340$ & 593 & 503(4), 473(18), 383(10), 353(24) & Apigenin- $C$-hexoside- $C$-hexoside & - & $0.050 \pm 0.004$ & - & VIII \\
\hline 11 & 13.4 & $294 / \operatorname{sh} 318$ & 685 & 523(100), 361(8), 179(4), 161(4), 135(3) & Speedoside & $0.30 \pm 0.02$ & - & - & I \\
\hline 12 & 14.1 & $228 / 264 / 296$ & 497 & 335(29), 221(21), 153(44), 109(21) & Protocatechuic acid derivative II & $1.4 \pm 0.1 \mathrm{a}$ & $0.67 \pm 0.04 \mathrm{c}$ & $1.6 \pm 0.1 \mathrm{~b}$ & II \\
\hline 13 & 15.0 & $222 / 262 / 296$ & 481 & 319(3), 153(100), 109(41) & Protocatechuic acid derivative III & - & - & $0.41 \pm 0.02$ & II \\
\hline 14 & 15.1 & $272 / 340$ & 563 & 473(16), 443(18), 383(24), 353(32) & Apigenin- $C$-hexoside- $C$-pentoside & - & $0.21 \pm 0.02$ & - & VIII \\
\hline 15 & 15.2 & $222 / 266 / 298$ & 451 & 297(30), 255(58), 195(71), 153(70), 109(21) & Protocatechuic acid derivative IV & - & - & $0.34 \pm 0.02$ & II \\
\hline 16 & 15.8 & $268 / 346$ & 563 & 473(6), 443(10), 383(18), 353(24), 297(2) & Apigenin- $C$-hexoside- $C$-pentoside & - & $0.11 \pm 0.01$ & - & VIII \\
\hline 17 & 16.0 & $284 / 352$ & 625 & 463(8), 301(49) & Quercetin- $O$-di-hexoside & - & - & $0.14 \pm 0.01$ & $\mathrm{~V}$ \\
\hline 18 & 16.6 & $284 / 352$ & 503 & 341(42), 179(100), 161(51), 135(41) & Dicaffeoyl-hexose & - & - & $0.25 \pm 0.03$ & I \\
\hline 19 & 18.1 & $282 / 350$ & 463 & $301(100)$ & Quercetin hexoside & - & - & $0.63 \pm 0.05$ & V \\
\hline 20 & 18.1 & $282 / 336$ & 609 & $447(8), 285(44)$ & Isoscutellarein- $O$-hexosyl-hexoside & - & $0.282 \pm 0.002$ & - & VIII \\
\hline 21 & 18.5 & $\operatorname{sh} 292 / 332$ & 623 & 461(49), 315(4), 161(26), 135(3) & Acteoside 0 & $0.067 \pm 0.005 \mathrm{c}$ & $0.30 \pm 0.02 \mathrm{~b}$ & $0.48 \pm 0.04 \mathrm{a}$ & I \\
\hline 22 & 18.6 & $260 / 330$ & 449 & $269(100)$ & Genistein derivative 0 & $0.041 \pm 0.005 \mathrm{~b}$ & $0.28 \pm 0.02 \mathrm{a}$ & $0.40 \pm 0.05 \mathrm{a}$ & VIII \\
\hline 23 & 19.5 & $\operatorname{sh} 296 / 328$ & 623 & 461(48), 315(5), 161(14), 135(1) & Isoacteoside & $0.11 \pm 0.01$ & - & - & I \\
\hline
\end{tabular}







Table 1.Retention time (Rt), wavelengths of maximum absorption $\left(\lambda_{\max }\right)$, mass spectral data, relative abundances of fragment ions, tentative identification and quantification of the phenolic compounds $V$. montana, $V$. polita and $V$. spuria methanolic extracts.

\begin{tabular}{|c|c|c|c|c|c|c|c|c|c|}
\hline \multirow{2}{*}{ Peak } & \multirow{2}{*}{ Rt (min) } & \multirow{2}{*}{$\lambda \max (\mathrm{nm})$} & \multirow{2}{*}[\mathrm{M}-\mathrm{H}]{$^{-}(m / z)$} & \multirow{2}{*}{$\operatorname{MS}^{2}(m / z)$} & \multirow{2}{*}{ Tentative identification } & \multicolumn{3}{|c|}{ Quantification (mg/g of dried plant) } & \multirow{2}{*}{$\begin{array}{l}\text { Standard used } \\
\text { for quantification }\end{array}$} \\
\hline & & & & & & V. montana & V.polita & V. spuria & \\
\hline \multicolumn{10}{|c|}{ Veronica montana } \\
\hline 1 & 5.4 & $\operatorname{sh} 298 / 326$ & 353 & 191(100), 179(67), 173(4), 161(5), 135(45) & 3-O-caffeoylquinic acid & $0.111 \pm 0.003$ & - & - & IV \\
\hline 2 & 5.8 & $224 / 263 / 294$ & 373 & 237(100), 195(7), 153(30), 109(7) & Protocatechuic acid derivative I & - & - & $0.52 \pm 0.01$ & II \\
\hline 3 & 6.0 & $\operatorname{sh} 298 / 328$ & 341 & 179(41), 161(100), 135(17) & Hexosyl-caffeic acid & - & $0.058 \pm 0.005 \mathrm{~b}$ & $0.32 \pm 0.02 \mathrm{a}$ & I \\
\hline 4 & 6.4 & $228 / 260 / 294$ & 153 & $109(100)$ & Protocatechuic acid* & $1.6 \pm 0.1 \mathrm{a}$ & - & $0.26 \pm 0.01 \mathrm{~b}$ & II \\
\hline 5 & 8.5 & $\operatorname{sh} 298 / 326$ & 353 & 191(100), 179(3), 161(3), 135(3) & 5-O-Caffeoylquinic acid* & $0.30 \pm 0.02 \mathrm{a}$ & $0.054 \pm 0.005 \mathrm{~b}$ & - & IV \\
\hline 6 & 9.7 & 256 & 137 & $93(100)$ & $p$-Hydroxybenzoic acid* & $0.18 \pm 0.02 \mathrm{a}$ & $0.076 \pm 0.002 \mathrm{~b}$ & - & III \\
\hline 7 & 10.2 & $296 / 326$ & 383 & 179(5), 161(100), 135(5) & Acetyl-hexosyl-caffeic acid & - & $0.038 \pm 0.004 \mathrm{~b}$ & $0.19 \pm 0.02 \mathrm{a}$ & I \\
\hline 8 & 10.7 & $300 / 326$ & 399 & 237(100), 179(13), 161(92),135(8) & Caffeic acid derivative & - & - & $0.42 \pm 0.03$ & I \\
\hline 9 & 11.9 & $\operatorname{sh} 298 / 324$ & 179 & $135(100)$ & Caffeic acid* & $0.28 \pm 0.02 \mathrm{a}$ & - & $0.15 \pm 0.01 \mathrm{~b}$ & I \\
\hline 10 & 12.6 & $266 / 340$ & 593 & 503(4), 473(18), 383(10), 353(24) & Apigenin- $C$-hexoside- $C$-hexoside & - & $0.050 \pm 0.004$ & - & VIII \\
\hline 11 & 13.4 & $294 / \operatorname{sh} 318$ & 685 & 523(100), 361(8), 179(4), 161(4), 135(3) & Speedoside & $0.30 \pm 0.02$ & - & - & I \\
\hline 12 & 14.1 & $228 / 264 / 296$ & 497 & 335(29), 221(21), 153(44), 109(21) & Protocatechuic acid derivative II & $1.4 \pm 0.1 \mathrm{a}$ & $0.67 \pm 0.04 \mathrm{c}$ & $1.6 \pm 0.1 \mathrm{~b}$ & II \\
\hline 13 & 15.0 & $222 / 262 / 296$ & 481 & 319(3), 153(100), 109(41) & Protocatechuic acid derivative III & - & - & $0.41 \pm 0.02$ & II \\
\hline 14 & 15.1 & $272 / 340$ & 563 & 473(16), 443(18), 383(24), 353(32) & Apigenin- $C$-hexoside- $C$-pentoside & - & $0.21 \pm 0.02$ & - & VIII \\
\hline 15 & 15.2 & $222 / 266 / 298$ & 451 & 297(30), 255(58), 195(71), 153(70), 109(21) & Protocatechuic acid derivative IV & - & - & $0.34 \pm 0.02$ & II \\
\hline 16 & 15.8 & $268 / 346$ & 563 & 473(6), 443(10), 383(18), 353(24), 297(2) & Apigenin- $C$-hexoside- $C$-pentoside & - & $0.11 \pm 0.01$ & - & VIII \\
\hline 17 & 16.0 & $284 / 352$ & 625 & 463(8), 301(49) & Quercetin- $O$-di-hexoside & - & - & $0.14 \pm 0.01$ & $\mathrm{~V}$ \\
\hline 18 & 16.6 & $284 / 352$ & 503 & 341(42), 179(100), 161(51), 135(41) & Dicaffeoyl-hexose & - & - & $0.25 \pm 0.03$ & I \\
\hline 19 & 18.1 & $282 / 350$ & 463 & $301(100)$ & Quercetin hexoside & - & - & $0.63 \pm 0.05$ & V \\
\hline 20 & 18.1 & $282 / 336$ & 609 & $447(8), 285(44)$ & Isoscutellarein- $O$-hexosyl-hexoside & - & $0.282 \pm 0.002$ & - & VIII \\
\hline 21 & 18.5 & $\operatorname{sh} 292 / 332$ & 623 & 461(49), 315(4), 161(26), 135(3) & Acteoside 0 & $0.067 \pm 0.005 \mathrm{c}$ & $0.30 \pm 0.02 \mathrm{~b}$ & $0.48 \pm 0.04 \mathrm{a}$ & I \\
\hline 22 & 18.6 & $260 / 330$ & 449 & $269(100)$ & Genistein derivative 0 & $0.041 \pm 0.005 \mathrm{~b}$ & $0.28 \pm 0.02 \mathrm{a}$ & $0.40 \pm 0.05 \mathrm{a}$ & VIII \\
\hline 23 & 19.5 & $\operatorname{sh} 296 / 328$ & 623 & 461(48), 315(5), 161(14), 135(1) & Isoacteoside & $0.11 \pm 0.01$ & - & - & I \\
\hline
\end{tabular}




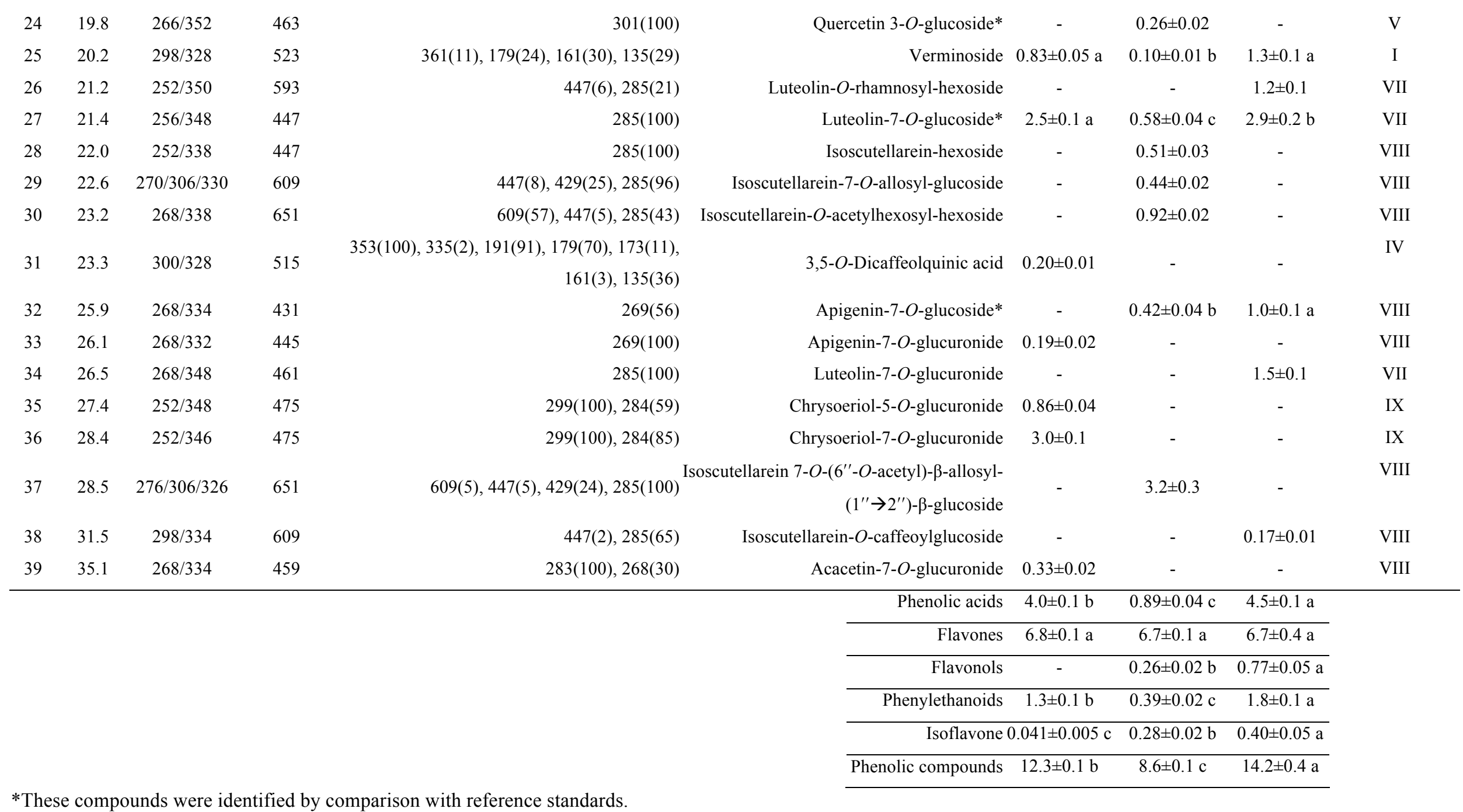

